Journal of the

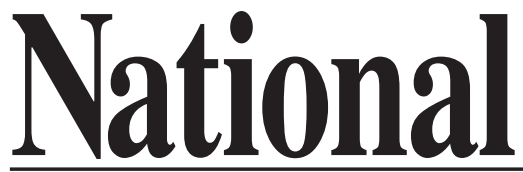

Academy or

Forensic
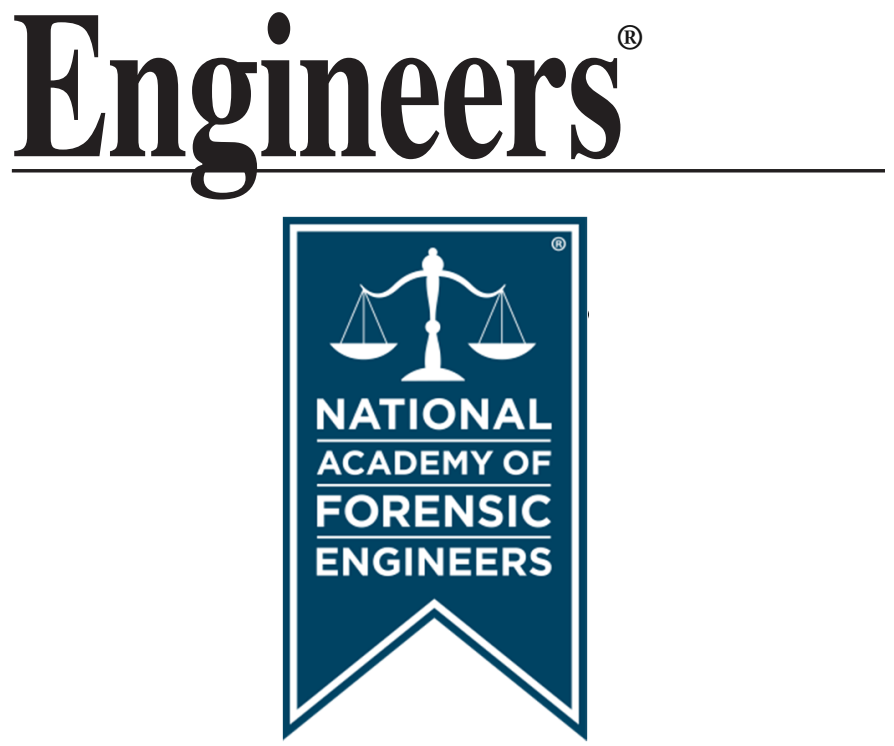

http://www.nafe.org ISSN: 2379-3252 


\title{
Forensic Engineering Analysis of Excessive Iron Corrosion in a Class of Automobile Engines
}

by Michael D. Leshner, P.E. (NAFE 559F)

\begin{abstract}
Automotive engine coolants are formulated to raise the boiling point, suppress the freezing point and protect the engine cooling passages and other cooling system materials from corrosion. Shortly after introducing a new coolant formulation across all models, a major auto manufacturer began receiving reports of a rusty sludge material fouling the cooling systems in one truck model line using one particular engine. The same model with a different engine did not experience the problem, nor did different models using the same engine. Many customers who owned the affected models experienced clogged heaters, fouled radiators, overheating, and in some cases, engine damage. A class-action lawsuit was initiated, leading to a forensic engineering investigation, with the objective of determining the actual root cause of excessive corrosion. The class included several hundred thousand potential plaintiffs and was represented by thirty five law firms. This paper will discuss the analysis and testing performed by the auto manufacturer, coolant supplier and this investigator. In this particular product defect case, a class action was appropriate because a large group of plaintiffs each suffered a relatively small individual economic loss.
\end{abstract}

\section{Background}

During the mid-1990s, most automobile manufacturers introduced a new "extended life" engine coolant formulation. Like conventional green anti-freeze, the new orange coolant is made from an ethylene glycol base. However, instead of depositing a layer of silicates to prevent corrosion, the new coolant formulation makes use of Organic Acid Technology, or OAT corrosion inhibitors.

Approximately one year after introducing the new OAT coolant, a major manufacturer began receiving reports of a rusty sludge material in the cooling systems of one vehicle model family. Curiously, the sludge problem did not appear in other models using the same engine, or in the same models using a different engine. The manufacturer enlisted help from their coolant supplier and set a "Corrosion Task Force" in motion to investigate the problem, its cause, and potential solutions. The manufacturer and coolant supplier worked jointly, 
Copyright ( National Academy of Forensic Engineers (NAFE) http://www.nafe.org. Redistribution or resale is illegal. Originally published in the Journal of the NAFE volume indicated on the cover page. ISSN: 2379-3252

because it was not clear whether the root cause was related to the coolant formulation or the engine configuration or both. This particular "rusty sludge" problem had not appeared in any other models, including some with the same engines, making the root cause difficult to identify.

In the affected vehicle models, sludge was observed on the radiator cap and inside the radiator as shown in figures 1 and 2. Problems in this class of vehicles appeared with one or more of the following symptoms:

- Rusty sludge on the radiator cap

- Rusty sludge inside the radiator, particularly inside the filler neck and upper tubes

- Radiator cap vacuum valve fails to close (sludge)

- Low coolant level

- Heater failure

- Engine overheating

\section{Personal Experience - Sludge}

The author owned one of the affected vehicles before becoming involved in the investigation. It was purchased second-hand with approximately 57,000 miles. Shortly after purchasing the truck, it experienced an overheating incident. The engine was shut down before permanent damage occurred. When the radiator cap was removed, it

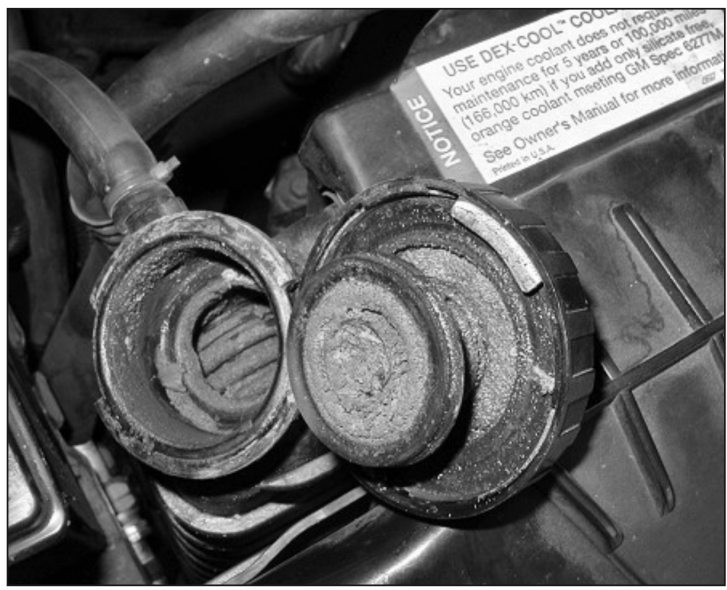

Figure 1

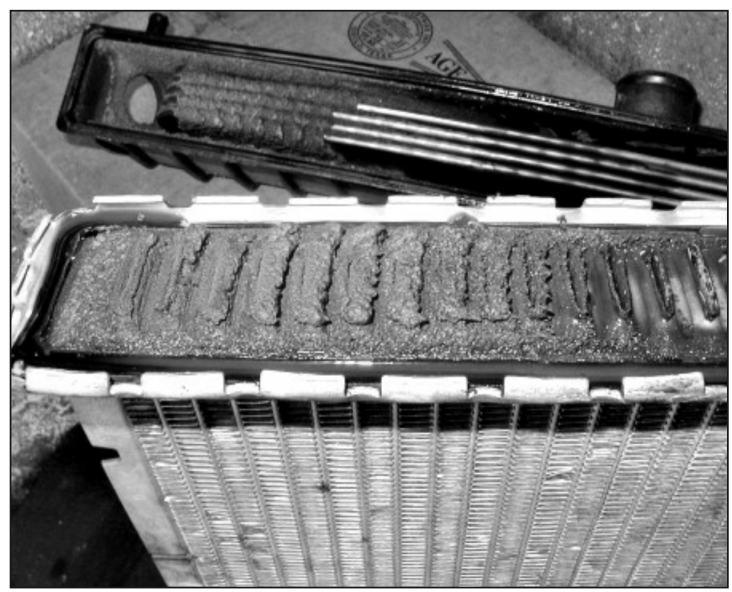

Figure 2 was covered with a dark red/brown sludge. The sludge occupied the entire filler neck of the radiator. The hose connecting the radiator to the recovery bottle was also plugged with sludge. 
In an attempt to correct the problem, the cooling system was flushed thoroughly with water and the radiator cap was replaced with a new one. The cooling system was re-filled with the specified (orange) coolant. Subsequently, the cooling system needed to be flushed approximately once per year, with replacement of the coolant.

\section{Task Force Investigation}

After the new coolant had been in the market for about a year, sludge deposits were being reported in vehicles with 20,000 to 30,000 miles, which is unusual and unexpected. Chemical analysis of the sludge confirmed that it was composed principally of iron oxide. Engine inspections suggested corrosion of the cast iron cylinder heads in stagnant areas. Some repair shops and dealers were switching back to the old (green) coolant after flushing the cooling system, which solved the problem.

The manufacturer explored several potential solutions to the problem, including;

- Re-formulation of the OAT coolant

- Addition of soluble oil to the coolant

- Switch to a hybrid Silicated/OAT extended life coolant

In a continuing investigation lasting several years, multiple factors were identified as related to the root cause, including:

- Low coolant levels

- Radiator caps that do not hold 15 psi

- Excessive (248+) coolant temperatures in drive, parked, traffic conditions

- Variation in fan clutch engagement

- Low coolant flow in the heads, especially at idle conditions

- Inadequate overflow bottle volume

No actual root cause was identified by the task force.

The Field Action (Technical Service Bulletin)

Six years after the first "sludge" models entered the market, the manufacturer released a Technical Service Bulletin, entitled:

"Rust in Cooling System, Heater Inoperative, Blows Cold Air, Engine Overheats (Flush Cooling System. The cause of the rust problem is described as follows: 
Copyright $\odot$ National Academy of Forensic Engineers (NAFE) http://www.nafe.org. Redistribution or resale is illegal. Originally published in the Journal of the NAFE volume indicated on the cover page. ISSN: 2379-3252

"Vehicles equipped with DEX-COOL ${ }^{\circledR}$ coolant, which may have been operated for extended periods of time with a low coolant level, usually in excess of $32,000 \mathrm{~km} \mathrm{20,000} \mathrm{miles),} \mathrm{may} \mathrm{be} \mathrm{susceptible} \mathrm{to} \mathrm{the}$ formation of a rust-like material in the cooling system."

The repair procedure specified in the Service Bulletin has 58 steps and includes installation of a different type of radiator cap with spring-loaded vacuum valve and a new thermostat. Rather than filling the cooling system as described in the Owners Manual, the coolant recovery bottle is to be filled to one inch above the "full hot" mark while the engine is cool. The Bulletin also includes the following instructions:

"Important: To assure intended system performance, inform the customer that the cooling system MUST be maintained in a completely full condition."

\section{Forensic Engineering Investigation}

In reviewing all the Corrosion Task Force investigations and findings, a common thread appeared to link all the suspected factors;

- Low coolant levels

- Radiator caps that do not hold 15 psi

- Excessive (248+) coolant temperatures in drive, parked, traffic conditions

- Variation in fan clutch engagement

- Low coolant flow in the heads, especially at idle conditions

- Inadequate overflow bottle volume

Each of these factors is either caused by or results from low coolant level, or both. The obvious question for the forensic engineer - Why is the coolant low? Once it became clear that there was likely to be a class-action lawsuit for damages caused by the sludge problem, the manufacturer took the position that low coolant was caused by poor owner maintenance.

\section{Testing}

To find the actual cause of low coolant, the author observed his own affected vehicle. After filling the cooling system and reservoir properly, the recovery bottle needed re-filling about every sixty days of use. Upon closer observation, it was clear that coolant was lost whenever the recovery bottle became over-filled, spilling coolant onto the ground. To understand the actual cause of the problem, one must consider all the functions of a standard radiator cap. Two different types of cap are shown in figure 3. Both have a spring-loaded 
Copyright @ National Academy of Forensic Engineers (NAFE) http://www.nafe.org. Redistribution or resale is illegal. Originally published in the Journal of the NAFE volume indicated on the cover page. ISSN: 2379-3252

\section{Normally Closed or Spring pressed Vacuum Valve Radiator Cap}
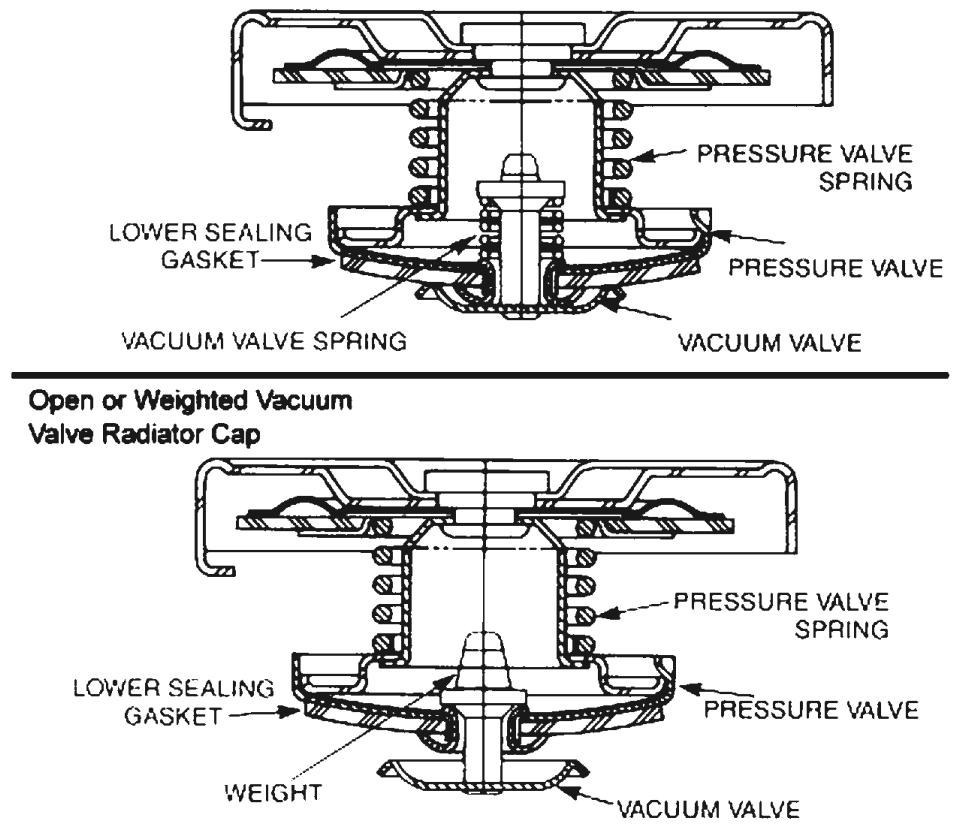

Figure 3

pressure relief valve to limit system pressure, and both have an upper seal to maintain a closed passage to the coolant recovery reservoir. At the bottom, both have a vacuum valve. The upper diagram has a spring-loaded vacuum valve and the lower diagram has a weighted vacuum valve.

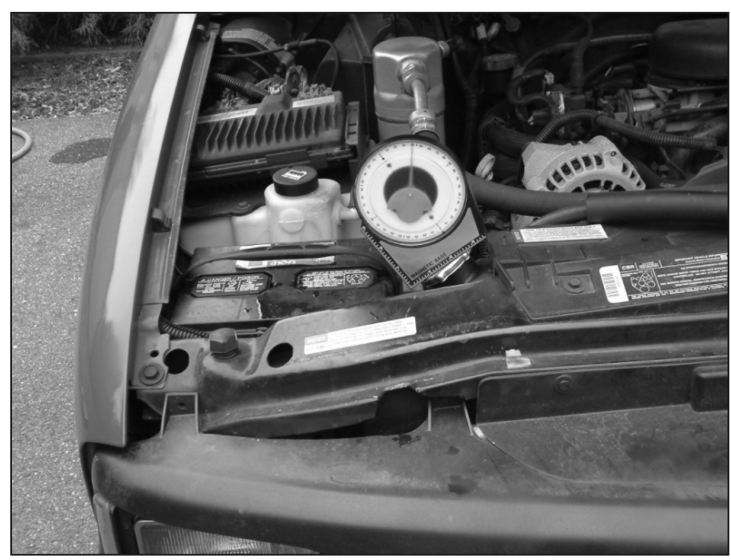

Figure 4

The affected vehicles were made with radiator caps having a weighted vacuum valve. The same vehicles also have radiator caps mounted at an angle of 36 degrees from the horizontal as shown in Figure 4. This cap orientation was a change from the prior model year, when the cap was horizontal. If the vacuum 
valve were not sealing properly, coolant would tend to over-fill the recovery reservoir and be lost from the system.

In order to assess whether the radiator cap vacuum valve performed differently when mounted at an angle, two series of tests were performed. The first was a bench test designed to measure leakage past the vacuum valve when mounted in both the horizontal and angled positions, shown in Figure 5. Coolant was transferred under a slight pressure from the plastic tank to the aluminum tank, and any leakage past the vacuum valve was measured. This test setup was intended to simulate the normal transfer of air and coolant from the radiator to the recovery bottle during operation.

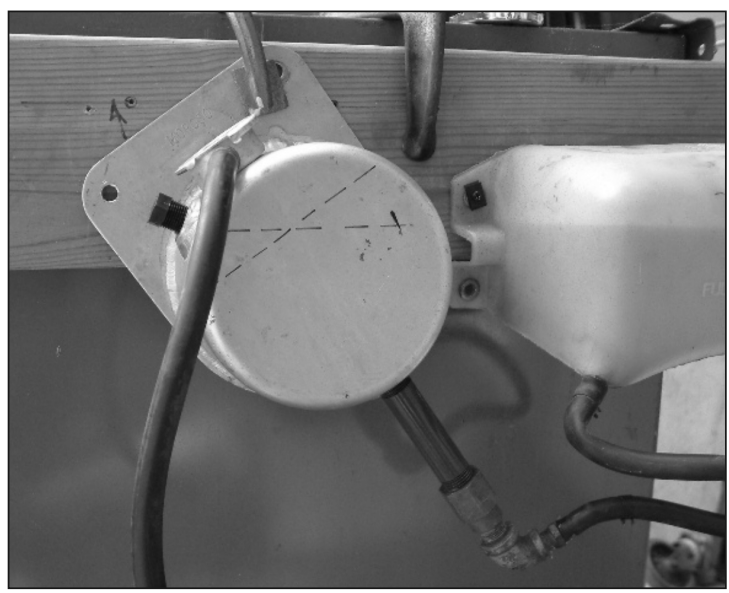

Figure 5

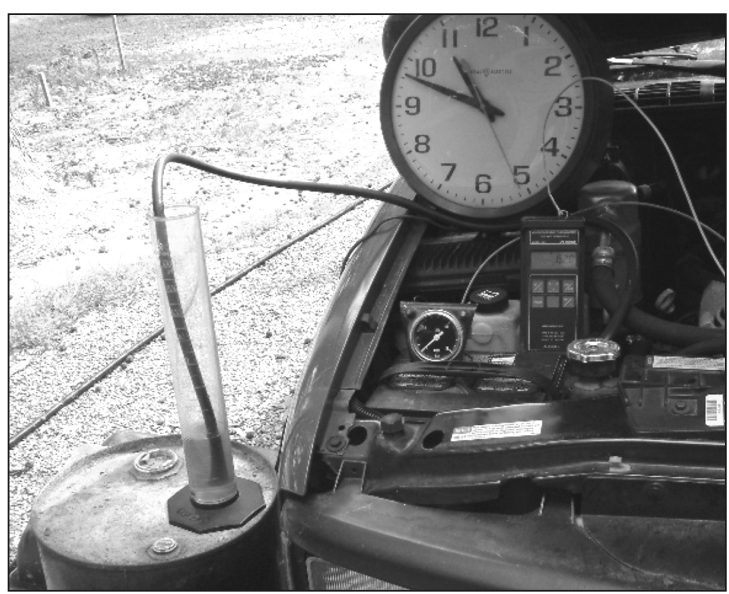

Figure 6

When mounted horizontally, the vacuum valve permitted air to escape and sealed promptly when the liquid level rose to the valve. No leakage was observed. When mounted at an angle, the valve leaked before sealing completely.

Another series of tests was performed on a vehicle, instrumented to measure cooling system pressure, temperature and leakage from the vacuum valve. The test setup is shown in Figure 6.

Note that the radiator cap is mounted horizontally in Figure 6. This was achieved by using a radiator from a prior model year. Leakage was measured after a cold start, at idle, in Drive. 
Copyright $\odot$ National Academy of Forensic Engineers (NAFE) http://www.nafe.org. Redistribution or resale is illegal. Originally published in the Journal of the NAFE volume indicated on the cover page. ISSN: 2379-3252

As shown in Figures 7 and 8, the orientation of the radiator cap has a strong influence on the performance of the vacuum valve. In the horizontal position (Figure 7), the vacuum valve properly allows air to escape and then promptly shuts to seal liquid coolant inside the radiator. Figure 8 is an example of runaway leakage past the vacuum valve.

Vacuum valve leakage tends to over-fill the coolant recovery reservoir, resulting in coolant loss.

\section{Conclusions}

1. Excessive iron corrosion in this group of vehicles is caused by operating with a low coolant level;

2. Low coolant levels result from vacuum valve leakage;

3. Once sludge begins to form, it accelerates coolant loss;

4. The use of a weighted vacuum valve is to be avoided in a radiator cap mounted at an angle.

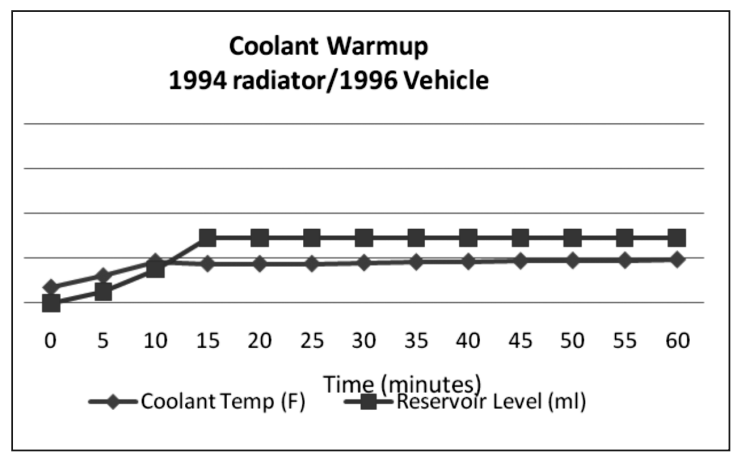

Figure 7

Radiator cap mounted horizontally

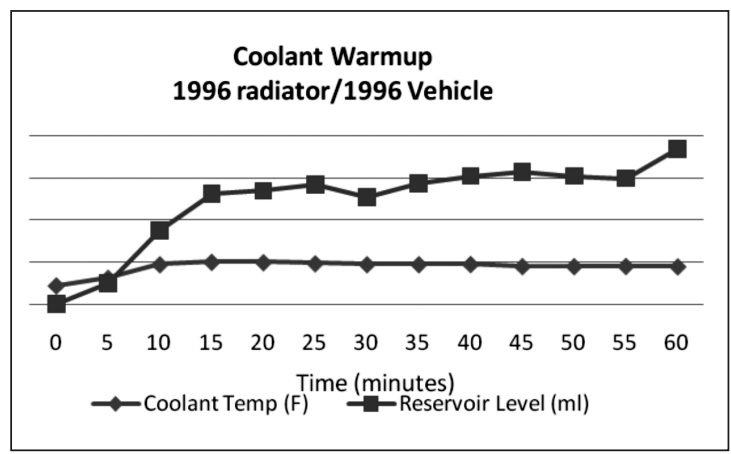

Figure 8

Radiator cap mounted at $36^{\circ}$ angle 